\title{
Water solubilization of hydrophobic nanocrystals by means of poly(maleic anhydride-alt-1-octadecene) $\dagger$
}

\author{
Riccardo Di Corato, $\ddagger$ Alessandra Quarta, $\ddagger$ Philomena Piacenza, Andrea Ragusa, Albert Figuerola, \\ Raffaella Buonsanti, Roberto Cingolani, Liberato Manna and Teresa Pellegrino*
}

\author{
Received 16th November 2007, Accepted 11th February 2008 \\ First published as an Advance Article on the web 13th March 2008 \\ DOI: $10.1039 / \mathrm{b} 717801 \mathrm{~h}$
}

\begin{abstract}
Poly(maleic anhydride-alt-1-octadecene), a cheap and commercially available polymer, was used to water-solubilize colloidal nanocrystals with various compositions, morphologies, and sizes. Highly pure nanoparticles with homogeneous distributions of sizes and surface charges were obtained after a single purification step of the polymer-coated particles by ultracentrifugation, saving precious time as compared to a previously published and similar polymer coating procedure. This simple strategy proved also to be generally applicable and represents a valid methodology to water-solubilize nanoparticles.
\end{abstract}

\section{Introduction}

Colloidal inorganic nanocrystals of different materials possess unique size-dependent properties that make them appealing candidates as imaging markers, therapeutic agents, and biosensor probes with potential applications in biology and medicine. ${ }^{1-6}$ Advances in nanocrystal research have been boosted by the development of novel preparation routes to colloidal nanocrystals, which nowadays can deliver nanoparticles with good control over size, shape, and composition, and even more complex nanostructures made of two or more domains, each of them of a different material, potentially conferring on them multiple properties. ${ }^{7,8}$ However, most of these approaches provide nanoparticles that are soluble in organic solvents, thus making their transfer into aqueous media a key issue for their exploitation in biology. Several strategies, based on different principles, have been developed for such a purpose, such as: i) the exchange of the surfactant coating on the nanoparticle surface with hydrophilic ligands; ${ }^{9-16}$ ii) the growth of a water-soluble protecting layer material around the original nanoparticle; ${ }^{17-19}$ iii) the inclusion of the hydrophobic nanoparticle in an amphiphilic polymeric shell. ${ }^{4,20-25}$ The latter procedure is perhaps more advantageous with respect to the others, as the nanoparticles are simply wrapped in a polymeric shell due to favourable interactions between the alkyl chains of the surfactant coating and the hydrophobic regions of the polymer, regardless of the type of surfactant and of the specific inorganic material that forms the nanocrystal core. Such a procedure is therefore easily extendable to different types of hydrophobic nanoparticles.

Our group demonstrated this concept by developing a polymer coating procedure for transferring different types of

NNL-National Nanotechnology Laboratory of CNR-INFM, Unità di ricerca IIT and Scuola Superiore ISUFI, Via per Arnesano, 73100 Lecce, Italy. E-mail: teresa.pellegrino@unile.it

$\dagger$ Electronic supplementary information (ESI) available: Additional TEM and gel electrophoresis images, DLS and FT-IR spectra. See DOI: $10.1039 / \mathrm{b} 717801 \mathrm{~h}$

† These authors contributed equally to this work. nanoparticles into water, ${ }^{20}$ and which consists of the following steps: i) poly(maleic anhydride-alt-1-tetradecene) (henceforth referred to as $\left.\mathrm{C}_{14}-\mathrm{P}\right)$ is added to the solution of nanocrystals in chloroform, after which the solvent is evaporated. This leads to intercalation of the polymeric (aliphatic) side chains among the surfactant molecules on the nanoparticle surface, with the anhydride groups exposed to the solvent; ii) a solution of a triamine (acting as cross-linker) in chloroform is added, followed again by solvent evaporation, addition of an aqueous borate buffer solution, and finally by sonication. This leads to crosslinking of the polymer chains around the nanoparticles, due to the formation of amide bonds between the anhydride groups of the polymer and the amine groups of the triamine; iii) the polymer-coated nanoparticles are purified from excess unbound polymer and unreacted cross-linker via gel permeation chromatography. While the approach is robust, cheap and generally applicable, unfortunately the polymer that was originally employed is not commercially available anymore and the extension of the original protocol to another amphiphilic polymer is not straightforward. As a result of a search for a polymer with similar structure that could be implemented for such a procedure, we report herein the results obtained when testing the commercially available poly(maleic anhydride-alt-1octadecene) (henceforth referred to as $\mathrm{C}_{18}-\mathrm{P}$ ) on colloidal nanocrystals of various compositions and shapes. This commercial polymer is similar to the original $\mathrm{C}_{14}-\mathrm{P}$, except for the alkyl side chain in each monomer unit, which is 18 carbons long instead of 14, and most remarkably for the molecular weight, which is about $7000 \mathrm{Da}$ in $\mathrm{C}_{14}-\mathrm{P}$, while it ranges from 30000 to $50000 \mathrm{Da}$ in $\mathrm{C}_{18}$-P (data supplied by Aldrich).

Here we show that, due to the differences between the two commercial polymers, the original coating procedure needed to be substantially modified in order to be extended successfully to the new polymer. In addition, due to the larger molecular weight of the polymer used in this procedure, a different purification strategy (based on ultracentrifugation) had to be employed. As proof of principle, the procedure has been applied to a range of nanocrystals with various compositions, morphologies, and sizes. 


\section{Results and discussion}

In the effort to adapt the previously reported procedure ${ }^{20}$ to the new polymer, first of all we found it necessary to work with more diluted solutions of nanocrystals, about $0.1 \mu \mathrm{M}$ instead of the previous $0.5 \mu \mathrm{M}$, in order to avoid inter-particle aggregation. Also, the amount of polymer monomer units added per square $\mathrm{nm}$ of nanocrystal surface was increased from the previous 100 to 300. This higher ratio can be understood by considering that if the same mass amount of the new $\mathrm{C}_{18}-\mathrm{P}$ polymer were added in the present approach as that used for $\mathrm{C}_{14}-\mathrm{P}$, then fewer polymer chains would be available now per nanoparticle surface area, since on average a polymeric chain of $\mathrm{C}_{18}-\mathrm{P}$ is much longer than a chain of $\mathrm{C}_{14}-\mathrm{P}$ (due to the difference in molecular weights). Also, we need to point out that it is important to work with a large excess of polymer molecules per nanoparticle to avoid wrapping of multiple nanoparticles within the same polymeric shell, with deleterious consequences for nanoparticle stability. As an example, when the number of polymer monomer units added per square $\mathrm{nm}$ of gold nanoparticle surface $(6 \mathrm{~nm}$ diameter) was reduced to 200 , the nanoparticles could still be transferred into water, but their solubility after purification was poor. Even worse, when under similar conditions larger iron oxide nanoparticles (with $8 \mathrm{~nm}$ average diameter) were transferred into borate buffer, the solution was cloudy and aggregates were observed by transmission electron microscopy (TEM) (data not shown).

Another remarkable difference with respect to the previous procedure is that, after evaporation of the cross-linker solution and addition of the borate buffer, we found that sonication at $60{ }^{\circ} \mathrm{C}$ for 60 up to $120 \mathrm{~min}$ was critical (as compared to $5 \mathrm{~min}$ at room temperature with $\left.\mathrm{C}_{14}-\mathrm{P}\right)^{20}$ in order to obtain a clear solution. Also, the former purification step based on size exclusion chromatography ${ }^{20}$ proved to be inefficient for the new $\mathrm{C}_{18}$ - $\mathrm{P}$ coated particles. In fact, when two buffer solutions, one containing $\mathrm{Au}$ nanoparticles (6 nm diameter) coated with $\mathrm{C}_{18}-\mathrm{P}$ and the other containing the same $\mathrm{Au}$ nanoparticles but coated with $\mathrm{C}_{14}-\mathrm{P}$, were passed through a sephacryl S-500 size exclusion column, the migration bands of the two purified samples on agarose gel showed that only in the $\mathrm{C}_{14}-\mathrm{P}$ coated sample had the polymer been completely removed, as no free polymer band could be observed in the gel (Fig. 1s, ESI $\dagger$ ). Although the colloidal stability of the $\mathrm{C}_{18}$-P coated nanoparticles purified on a size exclusion column is not impaired by the residues of free unbound polymer (for indeed the nanoparticles still migrate on the gel, see Fig. 1s, ESI $\dagger$ ), a more efficient purification for the $\mathrm{C}_{18}-\mathrm{P}$ coated nanocrystal was possible via ultracentrifugation on a sucrose gradient, which this time eliminated practically all the excess unbound polymer. We compared the effect of ultracentrifugation on different types of nanocrystals coated either with $\mathrm{C}_{14}-\mathrm{P}$ or with $\mathrm{C}_{18}-\mathrm{P}$ (see Fig. 1). After ultracentrifugation, the excess unbound polymer, which fluoresces blue under UV excitation, was visible on top of each gradient, whereas the nanoparticles had moved through the gradient until they reached a region of comparable density.

The gradient density and the centrifugation time had to be adjusted in every experiment, depending on the type of nanocrystal, in particular on its size and shape (Table 1). Fig. 1 also shows that, as expected, a larger excess of unbound polymer

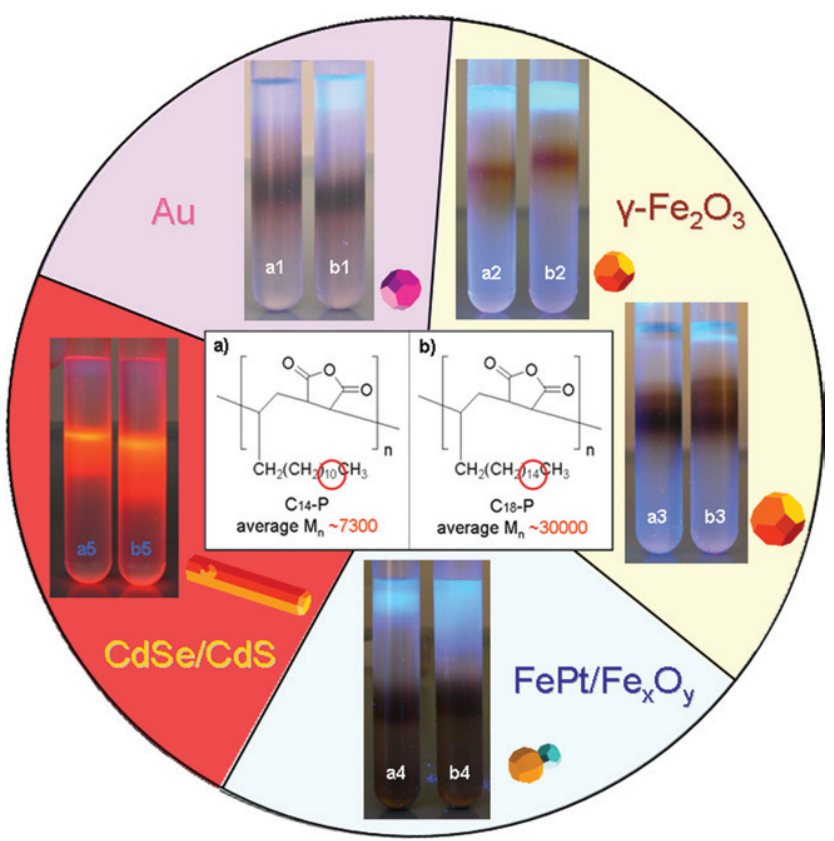

Fig. 1 Comparison of the effect of ultracentrifugation on different types of nanocrystals coated either with $\mathrm{C}_{14}-\mathrm{P}$ (a) or with $\mathrm{C}_{18}-\mathrm{P}$ (b). This was carried out on the following nanocrystals: Au spheres $(6 \mathrm{~nm}$ diameter, a1-b1), $\gamma-\mathrm{Fe}_{2} \mathrm{O}_{3}$ spheres (both $8 \mathrm{~nm}$ and $13 \mathrm{~nm}$ diameter, a2-b2 and a3-b3, respectively), heterodimers made of $\mathrm{FePt}_{-} \mathrm{Fe}_{x} \mathrm{O}_{y}(9 \mathrm{~nm}$ total length, a4-b4), and CdSe/CdS nanorods ( $5 \mathrm{~nm}$ diameter $\times 38 \mathrm{~nm}$ length, a5-b5).

Table 1 Conditions used for the purification of different polymer coated colloidal nanoparticles by ultracentrifugation

\begin{tabular}{lrlr}
\hline Sample & Size & Gradient density & Duration \\
\hline $\mathrm{Au}$ & $\sim 6 \mathrm{~nm}$ & $10-60 \%$ & $180 \mathrm{~min}$ \\
$\gamma-\mathrm{Fe}_{2} \mathrm{O}_{3}$ & $\sim 8 \mathrm{~nm}$ & $10-60 \%$ & $180 \mathrm{~min}$ \\
$\gamma-\mathrm{Fe}_{2} \mathrm{O}_{3}$ & $\sim 13 \mathrm{~nm}$ & $20-66 \%$ & $80 \mathrm{~min}$ \\
$\mathrm{FePt}_{-} \mathrm{Fe}_{x} \mathrm{O}_{y}$ & $\sim 9 \mathrm{~nm}$ & $10-60 \%$ & $150 \mathrm{~min}$ \\
$\mathrm{CdSe} / \mathrm{CdS}$ & $\sim 35 \times 5 \mathrm{~nm}$ & $20-66 \%$ & $150 \mathrm{~min}$ \\
\hline
\end{tabular}

was found on the upper layer of the sucrose gradient when working with $\mathrm{C}_{18}-\mathrm{P}$ instead of $\mathrm{C}_{14}-\mathrm{P}$.

TEM images of the $\mathrm{C}_{18}-\mathrm{P}$ coated particles deposited via evaporation of solutions on carbon-coated grids did not show the presence of aggregates (Fig. 2). From TEM, different organization patterns could be distinguished for the same nanoparticles before and after the polymer coating, and also depending on whether they were coated with $\mathrm{C}_{14}-\mathrm{P}$ or with $\mathrm{C}_{18}-\mathrm{P}$, probably because of the different thicknesses of the two coating layers (see also Fig. 2s, ESI $\dagger$ ).

In the case of spherical nanocrystals, the hydrodynamic diameter of the polymer-coated nanoparticles was evaluated by dynamic light scattering (DLS) (Table 2). An increase in diameter was always observed when switching from the surfactant-coated nanoparticles in the organic phase to the corresponding polymer-coated nanoparticles in the aqueous phase. Also, the $\mathrm{C}_{18}-\mathrm{P}$ coated particles were always slightly bigger than the corresponding $\mathrm{C}_{14}-\mathrm{P}$ coated ones (Table 2 ). 

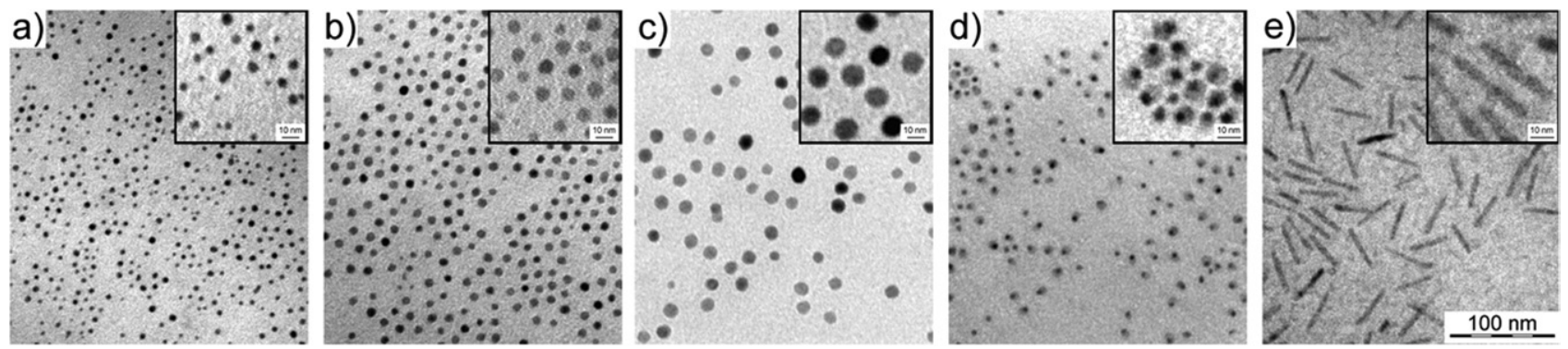

Fig. 2 TEM images of $\mathrm{C}_{18}-\mathrm{P}$ coated nanoparticles. a) Spherical Au nanoparticles of $5.4 \pm 1.0 \mathrm{~nm}$ diameter; spherical $\gamma$ - $\mathrm{Fe}_{2} \mathrm{O}_{3} \mathrm{NPs}$ of b) $8.2 \pm 0.8 \mathrm{~nm}$ diameter and c) $12.9 \pm 1.4 \mathrm{~nm}$ diameter; d) FePt-Fe $\mathrm{O}_{y}$ heterodimers of $8.7 \pm 0.8 \mathrm{~nm}$ total length; and e) CdSe/CdS nanorods of $5.2 \pm 0.7 \mathrm{~nm}$ diameter $\times 38.1 \pm 2.8 \mathrm{~nm}$ length. In all cases no aggregates are visible.

Table 2 DLS measurements performed on spherical Au and $\gamma-\mathrm{Fe}_{2} \mathrm{O}_{3}$ nanocrystals. The hydrodynamic radii of the nanoparticles were measured in the organic phase (toluene) and in the aqueous phase (borate buffer, $\mathrm{pH} 9$ ) after polymer coating with $\mathrm{C}_{14}-\mathrm{P}$ and $\mathrm{C}_{18}-\mathrm{P}$

\begin{tabular}{llll}
\hline & $\begin{array}{l}\mathrm{Au} \\
(5.4 \pm 1.0) \mathrm{nm}\end{array}$ & $\begin{array}{l}\gamma-\mathrm{Fe}_{2} \mathrm{O}_{3} \\
(8.2 \pm 0.8) \mathrm{nm}\end{array}$ & \multicolumn{1}{l}{$\begin{array}{l}\gamma-\mathrm{Fe}_{2} \mathrm{O}_{3} \\
(12.9 \pm 1.4) \mathrm{nm}\end{array}$} \\
\hline organic & $7.6 \pm 1.8$ & $9.2 \pm 0.6$ & $12.9 \pm 0.8$ \\
$\mathrm{C}_{14}-\mathrm{P}$ & $13.6 \pm 1.6$ & $17.9 \pm 0.3$ & $22.5 \pm 0.1$ \\
$\mathrm{C}_{18} \mathrm{P}$ & $15.8 \pm 1.1$ & $19.7 \pm 0.3$ & $28.7 \pm 1.9$ \\
\hline
\end{tabular}

The difference in size was also confirmed by gel electrophoresis (Fig. 3), as the $\mathrm{C}_{18} \mathrm{P}$ coated nanoparticles were always slightly more retained than the corresponding $\mathrm{C}_{14}-\mathrm{P}$ coated ones. All the migration bands corresponding to the purified $\mathrm{C}_{18}-\mathrm{P}$ coated nanoparticles are as narrow as those corresponding to the same particles but coated with $\mathrm{C}_{14}-\mathrm{P}$, indicating that also the new polymer coating yields water-soluble nanoparticles with rather narrow distributions of sizes and surface charges. Furthermore, by looking at the same gel under a blue filter light (Fig. 3, panel c) we could confirm that all the excess unbound polymer had been removed, since no fluorescence arising from free polymer could be observed, as opposed to the case of non-purified samples (Fig. 3s, ESI $\dagger$ ).

The charge distribution on the surface of the nanoparticles was also investigated by means of zeta potential measurements
(Table 3). The data obtained indicate the presence of a negatively charged surface for both $\mathrm{C}_{14}-\mathrm{P}$ and $\mathrm{C}_{18}-\mathrm{P}$ coated particles, due to the hydrolyzed carboxylic groups formed by the ring opening of the maleic anhydrides. In general, the $\mathrm{C}_{18}$-P coated particles have a higher negative surface charge, probably due to the presence of more carboxylic groups per polymer chain in $\mathrm{C}_{18}-\mathrm{P}$ than in $\mathrm{C}_{14}-\mathrm{P}$ upon hydrolyzation.

The optical properties of the polymer-coated fluorescent nanorods were also investigated by adsorption and emission spectroscopy (Fig. 4). The water-soluble nanocrystals presented basically the same characteristics, independently of the polymer used, and no significant shifts in the absorption profile were

Table 3 Zeta potential measurements expressed in $\mathrm{mV}$ in borate buffer of the nanocrystals coated with $\mathrm{C}_{14}-\mathrm{P}$ and with $\mathrm{C}_{18}-\mathrm{P}$

\begin{tabular}{lcc}
\hline Sample & $\zeta$-Potential & std \\
\hline $\mathrm{Au}-\mathrm{C}_{14}-\mathrm{P}$ & -13.3 & \pm 0.9 \\
$\mathrm{Au}-\mathrm{C}_{18}-\mathrm{P}$ & -15.6 & \pm 1.8 \\
$\gamma-\mathrm{Fe}_{2} \mathrm{O}_{3} 8 \mathrm{~nm}-\mathrm{C}_{14}-\mathrm{P}$ & -18.3 & \pm 1.8 \\
$\gamma-\mathrm{Fe}_{2} \mathrm{O}_{3} 8 \mathrm{~nm}-\mathrm{C}_{18}-\mathrm{P}$ & -22.3 & \pm 1.7 \\
$\gamma-\mathrm{Fe}_{2} \mathrm{O}_{3} 13 \mathrm{~nm}-\mathrm{C}_{14}-\mathrm{P}$ & -23.7 & \pm 0.7 \\
$\gamma-\mathrm{Fe}_{2} \mathrm{O}_{3} 13 \mathrm{~nm}-\mathrm{C}{ }_{18}-\mathrm{P}$ & -26.0 & \pm 1.4 \\
$\mathrm{FePt}-\mathrm{Fe}_{x} \mathrm{O}_{y}-\mathrm{C}_{14}-\mathrm{P}$ & -16.0 & \pm 1.8 \\
$\mathrm{FePt}-\mathrm{Fe} \mathrm{O}_{y}-\mathrm{C}_{18}-\mathrm{P}$ & -17.4 & \pm 0.7 \\
$\mathrm{CdSe} / \mathrm{CdS}-\mathrm{C}_{14}-\mathrm{P}$ & -24.5 & \pm 1.9 \\
$\mathrm{CdSe} / \mathrm{CdS}-\mathrm{C}_{18}-\mathrm{P}$ & -28.0 & \pm 1.5 \\
\hline
\end{tabular}
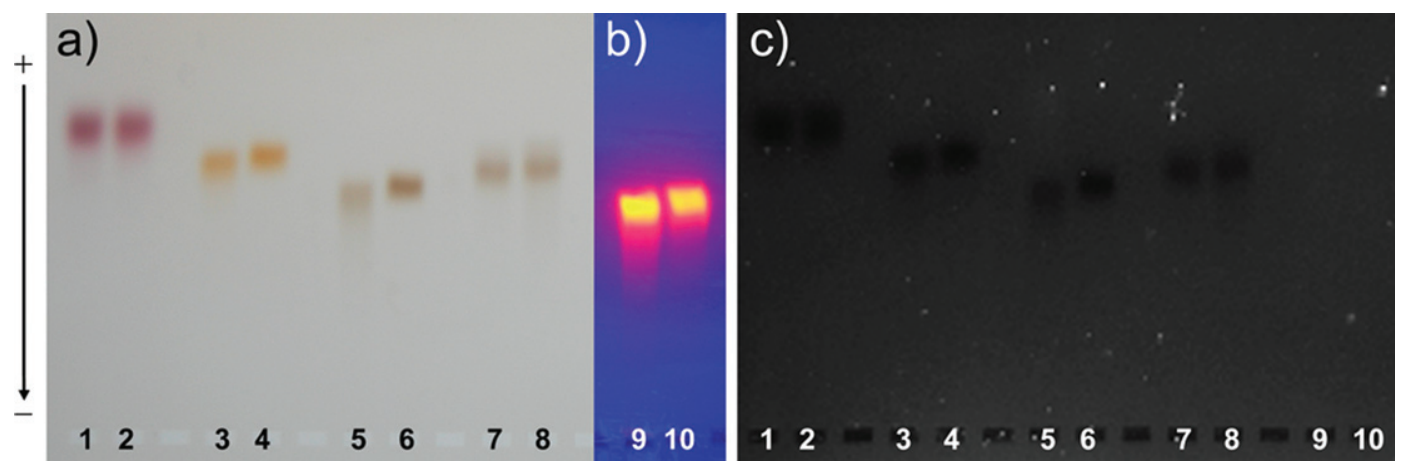

Fig. 3 Gel migration of different types of nanoparticles coated with $\mathrm{C}_{18}-\mathrm{P}$ (lines 1, 3, 5, 7, 9) and $\mathrm{C}_{14}-\mathrm{P}$ (lines 2, 4, 6, 8, 10). Au spheres of $6 \mathrm{~nm}$ (lines 1 and 2), $\gamma-\mathrm{Fe}_{2} \mathrm{O}_{3}$ spheres of $8 \mathrm{~nm}$ (lines 3 and 4) and $13 \mathrm{~nm}$ (lines 5 and 6), and $\mathrm{FePt}-\mathrm{Fe}_{x} \mathrm{O}_{y}$ heterodimers of $9 \mathrm{~nm}$ total length (lines 7 and 8 ) are detected under visible light (panel a); CdSe/CdS nanorods of $5 \mathrm{~nm}$ diameter $\times 38 \mathrm{~nm}$ length (lines 9 and 10) are detected under a UV orange filter (panel b). No excess free polymer is observed for all the nanoparticles purified by ultracentrifugation, as confirmed by the absence of a signal under a blue filter (panel c). 

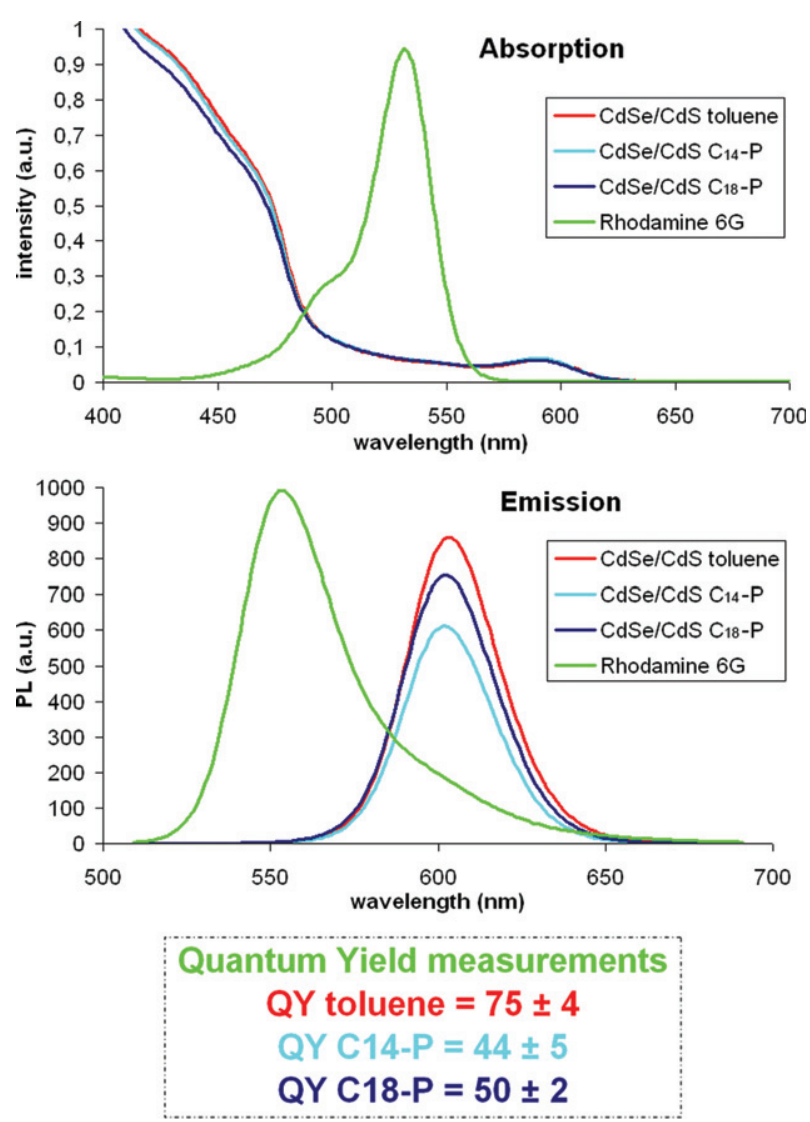

Fig. 4 Absorption (top) and emission (bottom) spectra of CdSe/CdS nanorods in toluene (red curve) and of the same nanorods in borate buffer when the particles are coated with $\mathrm{C}_{14}-\mathrm{P}$ (light blue curve) and with $\mathrm{C}_{18} \mathrm{P}$ (dark blue curve). The absorption and emission spectra of rhodamine $6 \mathrm{G}$ in water are also reported (green curve). The QYs of $\mathrm{C}_{14}-\mathrm{P}$ and $\mathrm{C}_{18}-\mathrm{P}$ samples were calculated at three different concentrations of the rods and of the standard (specifically at optical densities equal to $0.2,0.1$ and 0.05 at $488 \mathrm{~nm}$ for all samples). The QY for each sample was estimated as the average of the three measurements.

observed when passing from toluene to the aqueous phase. Instead, a modest blue-shift (from 2 to $3 \mathrm{~nm}$ ) of the maximum of the emission peak ( $\lambda_{\mathrm{exc}}=488 \mathrm{~nm}$ ) was observed when passing from the organic to the aqueous phase. For measuring the quantum yield of the $\mathrm{CdSe} / \mathrm{CdS}$ nanorods, rhodamine $6 \mathrm{G}$ was used as standard. The quantum yield (QY) of the water-soluble nanorods was lower than that of the starting sample in toluene, in line with several previous works in which a similar effect was observed upon surface functionalization of as-grown fluorescent nanocrystals.

The FT-IR spectra of the $\mathrm{C}_{18}-\mathrm{P}$ and of the $\mathrm{C}_{14}-\mathrm{P}$ coated nanocrystals were also recorded and it was confirmed that the same type of functional groups should be exposed to the aqueous medium since the spectra presented the same absorption peaks (Fig. 5s, ESI $\dagger$ ).

In order to assess that the new polymer coating procedure yielded water-soluble nanoparticles that could be further functionalized, mono-amino poly(ethylene glycol) (PEG) molecules were successfully conjugated to the $\mathrm{C}_{18}-\mathrm{P}$ coated nanoparticles. Gel electrophoresis analysis showed that, by increasing the amount of the coupling agent, more PEG molecules were attached to each nanoparticle, as indicated by the more retained bands (Fig. 6s, ESI $\dagger$ ). ${ }^{26}$ Nevertheless, the migration bands were as narrow as those obtained with the $\mathrm{C}_{14}-\mathrm{P}$ polymer, indicating that the two samples present the same chemical reactivity, which can be exploited for bioconjugation of biologically important molecules (e.g. antibodies, specific receptors, and so on).

\section{Experimental}

\section{Chemicals}

Poly(maleic anhydride-alt-1-octadecene) (\#419117), poly(maleic anhydride-alt-1-tetradecene) (\#45.251-3, not commercially available any more), bis(hexamethylene)triamine (\#14506), sucrose (\#16104), sodium tetraborate decahydrate (\#S9640), boric acid (\#B1934), $N$-(3-dimethylaminopropyl)- $N$-ethylcarbodiimide hydrochloride (EDC, \#E7750), monoamino-PEG (MW $\left.750 \mathrm{~g} \mathrm{~mol}^{-1}, \# 07964\right)$ and Tris-borate-EDTA buffer (TBE buffer, \#T3913) were purchased from Sigma-Aldrich. Agarose (D-1 low EEO, \#C1349) was purchased from Eppendorf. All solvents were purchased from J.T. Baker.

\section{Instruments}

Ultracentrifugation was performed on a Beckman Coulter Optima $^{\mathrm{TM}}$ LE-80 K ultracentrifuge equipped with a SW41 Ti rotor, at a speed of $30000 \mathrm{rpm}$, corresponding to $150000 \mathrm{rcf}$ (relative centrifugal force). Low-magnification TEM images were recorded on a JEOL Jem 1011 microscope operated at an accelerating voltage of $100 \mathrm{kV}$. TEM samples were prepared by dropping a dilute solution of nanocrystals in water on carbon-coated copper grids (Formvar/Carbon $300 \mathrm{Mesh} \mathrm{Cu}$ ) and by letting the solvent evaporate. Gel electrophoresis analysis was performed on a Bio-Rad system (Gel Doc). Prior to gel electrophoresis, a solution containing Orange $\mathrm{G}$ and $30 \%$ glycerol in gel-loading buffer corresponding to $20 \%$ of the sample volume was added to each sample. The samples were run on $1 \%$ agarose gel if not purified, or on $2 \%$ agarose gel if purified by ultracentrifugation. The agarose gel was prepared by dissolving the agarose powder in TBE buffer. The electrophoretic run was carried out for $60 \mathrm{~min}$ at $100 \mathrm{~V}$. Visible light was used to detect gold, iron oxide, and $\mathrm{FePt}-\mathrm{Fe}_{x} \mathrm{O}_{y}$ nanoparticles, while UV light under an orange filter was used to detect the red emitting $\mathrm{CdSe} /$ CdS nanorods. Finally, UV light under a blue filter was used to detect the blue emitting excess of polymer. Zeta potential and DLS measurements were performed on a Zetasizer Nano ZS90 (Malvern, USA) equipped with a $4.0 \mathrm{~mW} \mathrm{He-Ne} \mathrm{laser} \mathrm{operating}$ at $633 \mathrm{~nm}$ and an Avalanche photodiode detector. Measurements were made at $25^{\circ} \mathrm{C}$ on borate saline buffered solutions $(\mathrm{pH}=9)$ of the particles. The values were determined using the Smoluchowsky approximation $(f(k a)=1.5)$, and were estimated as the average of twenty repeated measurements. FT-IR spectroscopy measurements were carried out on polymer-coated nanoparticles using a Bruker Equinox 70 FT-IR apparatus operating in absorption mode at a resolution of $4 \mathrm{~cm}^{-1}$. A peak deconvolution procedure was applied to the spectra using the Levenberg-Marquardt method. ${ }^{27}$ UV-vis absorption spectra were measured using a Varian Cary $300 \mathrm{UV}$-Vis spectrophotometer. Photoluminescence (PL) spectra were recorded on a Cary Eclipse spectrophotometer. 


\section{Synthesis of different nanoparticles}

Colloidal Au nanocrystals were synthesized according to standard procedures. ${ }^{28,29}$ To obtain monodisperse nanocrystals with a diameter of about $6 \mathrm{~nm}$ the procedure was slightly modified (this is also described in the supplementary information of ref. 20). Standard procedures were also followed to synthesize $\gamma-\mathrm{Fe}_{2} \mathrm{O}_{3}$ (8 nm diameter) ${ }^{30} \mathrm{CdSe} / \mathrm{CdS},{ }^{31}$ and $\mathrm{FePt}-\mathrm{Fe}_{x} \mathrm{O}_{y}$ nanocrystals. ${ }^{32}$ In order to prepare colloidal $\gamma-\mathrm{Fe}_{2} \mathrm{O}_{3}$ nanoparticles of $13 \mathrm{~nm}$ in diameter, the seed-mediated growth method $^{33}$ was followed, starting from previously synthesized nanoparticles of $8 \mathrm{~nm}$ in diameter.

\section{Polymer coating procedure}

A solution of poly(maleic anhydride-alt-1-octadecene) in chloroform at an initial concentration of polymer monomer units equal to $0.137 \mathrm{M}$ was added to a solution of surfactant-coated nanocrystals in chloroform, at a concentration of $0.1 \mu \mathrm{M}$, in order to reach a ratio of polymer monomer units per $\mathrm{nm}^{2}$ of nanocrystal surface equal to 300 . After slow evaporation of the solvent under controlled pressure (using a rotavapor), a solution of bis(hexamethylene)triamine in chloroform, at a concentration of $0.020 \mathrm{M}$, was added to reach a ratio of cross-linker molecules per $\mathrm{nm}^{2}$ of nanocrystal surface equal to 10 . Chloroform was added to the solution to reach a final concentration of nanoparticles of about $0.5 \mu \mathrm{M}$. After sonicating for $30 \mathrm{~min}$, the solvent was again removed under controlled pressure (using a rotavapor). A thin film of nanoparticles collected on the walls of the flask indicated the complete removal of the solvent. Sodium borate buffer ( $50 \mathrm{mM}, \mathrm{pH}$ 9) was added until it covered the solid layer of nanoparticles in the reaction flask and the resulting mixture was sonicated at $60{ }^{\circ} \mathrm{C}$ for 60 up to $120 \mathrm{~min}$, depending on the sample. The solution was then filtered on syringe filters ( 0.45 and $0.22 \mu \mathrm{m}$ pore sizes) in order to remove possible large aggregates. To remove the excess cross-linker molecules and also excess unbound polymer molecules, two washing steps were carried out on a centrifuge tube equipped with a cellulose membrane (Amicon Ultra-15, Millipore) with molecular weight cut-off that were slightly smaller than the average molecular weight of the nanocrystals. In order to completely remove the excess unbound polymer, the solution of nanoparticles in buffer was concentrated to a few millilitres, and was then ultracentrifuged (using a Beckman Coulter Optima $^{\mathrm{TM}}$ LE-80 K ultracentrifuge) at $150000 \mathrm{rcf}$ on a continuous sucrose gradient. The gradient density range $(5-66 \%)$ and the duration of centrifugation step (1-4h) varied in each experiment and depended both on the material and on the size of the nanoparticles that were used (see Table 1 for the conditions followed for each nanocrystal sample). The layer of nanoparticles was recovered from the gradient with a pipette and was washed twice through a centrifuge filter tube in order to clean the sample from sucrose and to dissolve it in the desired medium.

The sucrose gradient was prepared by using a peristaltic pump and by starting from a sucrose stock solution corresponding to the lowest concentration of sucrose for that gradient. This solution of sucrose was then mixed with a solution of sucrose corresponding to the highest concentration for that gradient at a flow rate of $0.5 \mathrm{~mL} \mathrm{~min} \mathrm{~m}^{-1}$ until a ultracentrifuge tube of about $12 \mathrm{~mL}$ was filled.
It is worth noting that the initial concentration of the iron oxide nanoparticles and of the $\mathrm{FePt}-\mathrm{Fe}_{x} \mathrm{O}_{y}$ dimers was determined by elemental analysis, by measuring the amount of iron and platinum in the nanostructures, while in the case of $\mathrm{Au}$ nanoparticles the concentration was determined by recording the absorption spectra, since the optical extinction coefficient for $\mathrm{Au}$ is known $\left(\epsilon=10^{7} \mathrm{M}^{-1} \mathrm{~cm}^{-1}\right.$ at a wavelength of $520 \mathrm{~nm}$ ). In the case of $\mathrm{CdSe} / \mathrm{CdS}$ nanorods the concentration was estimated by taking into account the concentration of CdSe seeds (each $\mathrm{CdSe} / \mathrm{CdS}$ nanorod contains a spherical CdSe seed inside, and therefore the final concentration of nanorods can be extrapolated by knowing the amount of CdSe seeds used for their synthesis, see ref. 31 for details). Alternatively, the extinction coefficient of the core/shell CdSe/CdS nanorods could be approximated to that of spherical CdSe nanocrystals with a diameter equal to the diameter of the core/shell nanorods. This should represent a rather acceptable approximation as long as the CdS shell along the radial direction is not thicker than a few monolayers (as in the case of the nanorods exploited in this work) and if the excitation energy is not deep in the UV region, where predominant absorption from the $\mathrm{CdS}$ shell is expected.

\section{Conclusions}

This work presents a comparative study between polymer coated nanoparticles which were made water-soluble by exploiting poly(maleic anhydride-alt-1-octadecene), a cheap and commercially available polymer, and a similar one, poly(maleic anhydride-alt-1-tetradecene), previously used, ${ }^{20}$ which is not commercially available anymore. The procedure has been substantially modified in order to be adapted to the poly(maleic anhydride-alt-1-octadecene) polymer. Furthermore, the purification process required improvement with respect to the previously reported one as the new polymer had a higher molecular weight than the previous $\mathrm{C}_{14}-\mathrm{P}$ polymer used and an higher excess of polymer is needed in order to obtain individual non-aggregated polymer coated nanoparticles. By using a single ultracentrifugation step, the entire water-solubilizing process was faster, more efficient, and reproducible and it yielded nanoparticles with narrow distributions in both sizes and surface charges. The procedure was tested on several types of nanocrystals with different composition, morphology, and shape, and proved to be quite general. Furthermore, the water-soluble nanocrystals should preserve the physical properties of their lipophilic counterparts (we proved for instance that the fluorescence of semiconductor nanorods was retained upon polymer coating), and therefore they are ready for efficient conjugation to biological molecules.

\section{Acknowledgements}

This work was supported by the Italian Ministry of Research (FIRB grants RBN01 KJHT-007, RBIN048 TSE and RBLA03ER38) and by the European STREP project SA-NANO (contract number 013698). The authors are grateful to Prof. Michele Maffia and Dr Antonia Rizzello for the assistance with ultracentrifugation and to Dr Luigi Carbone for help with the CdSe/CdS nanorod synthesis. 


\section{References}

1 I. L. Medintz, H. T. Uyeda, E. R. Goldman and H. Mattoussi, Nat. Mater., 2005, 4, 435-446.

2 A. H. Lu, E. L. Salabas and F. Schuth, Angew. Chem., Int. Ed., 2007, 46, 1222-1244.

3 J. M. Klostranec and W. C. W. Chan, Adv. Mater., 2006, 18, $1953-$ 1964.

4 X. H. Gao, Y. Y. Cui, R. M. Levenson, L. W. K. Chung and S. M. Nie, Nat. Biotechnol., 2004, 22, 969-976.

5 X. Michalet, F. F. Pinaud, L. A. Bentolila, J. M. Tsay, S. Doose, J. J. Li, G. Sundaresan, A. M. Wu, S. S. Gambhir and S. Weiss, Science, 2005, 307, 538-544.

6 N. L. Rosi and C. A. Mirkin, Chem. Rev., 2005, 105, $1547-1562$.

7 P. D. Cozzoli, T. Pellegrino and L. Manna, Chem. Soc. Rev., 2006, 35, 1195-1208

8 Y. Yin and A. P. Alivisatos, Nature, 2005, 437, 664-670.

9 F. Pinaud, D. King, H. P. Moore and S. Weiss, J. Am. Chem. Soc., 2004, 126, 6115-6123.

$10 \mathrm{~W}$. Jiang, S. Mardyani, H. Fischer and W. C. W. Chan, Chem. Mater., 2006, 18, 872-878.

11 A. M. Smith, H. W. Duan, M. N. Rhyner, G. Ruan and S. M. Nie, Phys. Chem. Chem. Phys., 2006, 8, 3895-3903.

12 G. P. Mitchell, C. A. Mirkin and R. L. Letsinger, J. Am. Chem. Soc., 1999, 121, 8122-8123.

13 D. M. Willard, L. L. Carillo, J. Jung and A. Van Orden, Nano Lett., 2001, 1, 469-474.

14 J. Aldana, Y. A. Wang and X. G. Peng, J. Am. Chem. Soc., 2001, 123, 8844-8850.

15 H. Mattoussi, J. M. Mauro, E. R. Goldman, G. P. Anderson, V. C. Sundar, F. V. Mikulec and M. G. Bawendi, J. Am. Chem. Soc., 2000, 122, 12142-12150.

16 S. Pathak, S. K. Choi, N. Arnheim and M. E. Thompson, J. Am Chem. Soc., 2001, 123, 4103-4104.

17 W. J. Parak, D. Gerion, D. Zanchet, A. S. Woerz, T. Pellegrino, C. Micheel, S. C. Williams, M. Seitz, R. E. Bruehl, Z. Bryant, C. Bustamante, C. R. Bertozzi and A. P. Alivisatos, Chem. Mater., $2002,14,2113-2119$.
18 W. Z. Guo, J. J. Li, Y. A. Wang and X. G. Peng, Chem. Mater., 2003, 15, 3125-3133.

19 L. M. LizMarzan, M. Giersig and P. Mulvaney, Langmuir, 1996, 12, 4329-4335.

20 T. Pellegrino, L. Manna, S. Kudera, T. Liedl, D. Koktysh, A. L. Rogach, S. Keller, J. Radler, G. Natile and W. J. Parak, Nano Lett., 2004, 4, 703-707.

21 B. Dubertret, P. Skourides, D. J. Norris, V. Noireaux, A. H. Brivanlou and A. Libchaber, Science, 2002, 298, 1759-1762.

22 W. W. Yu, E. Chang, J. C. Falkner, J. Y. Zhang, A. M. Al-Somali, C. M. Sayes, J. Johns, R. Drezek and V. L. Colvin, J. Am. Chem Soc., 2007, 129, 2871-2879.

23 X. Y. Wu, H. J. Liu, J. Q. Liu, K. N. Haley, J. A. Treadway, J. P. Larson, N. F. Ge, F. Peale and M. P. Bruchez, Nat. Biotechnol., 2003, 21, 41-46.

24 S. F. Wuister, I. Swart, F. van Driel, S. G. Hickey and C. D. Donega, Nano Lett., 2003, 3, 503-507.

25 D. R. Larson, W. R. Zipfel, R. M. Williams, S. W. Clark, M. P. Bruchez, F. W. Wise and W. W. Webb, Science, 2003, 300, 1434-1436.

26 R. A. Sperling, T. Pellegrino, J. K. Li, W. H. Chang and W. J. Parak, Adv. Funct. Mater., 2006, 16, 943-948.

27 P. R. Gill, W. Murray and M. H. Wright, Pratical Optimization, Academic Press, London, Editon edn, 1981, pp. 136-137.

28 M. Brust, M. Walker, D. Bethell, D. J. Schiffrin and R. Whyman, J. Chem. Soc., Chem. Commun., 1994, 801-802.

29 J. Fink, C. J. Kiely, D. Bethell and D. J. Schiffrin, Chem. Mater., 1998, 10, 922-926.

30 S. H. Sun and H. Zeng, J. Am. Chem. Soc., 2002, 124, 8204-8205.

31 L. Carbone, C. Nobile, M. De Giorgi, F. Della Sala, G. Morello, P. Pompa, M. Hytch, E. Snoeck, A. Fiore, I. R. Franchini, M. Nadasan, A. F. Silvestre, L. Chiodo, S. Kudera, R. Cingolani, R. Krahne and L. Manna, Nano Lett., 2007, 7, 2942-2950.

32 A. Figuerola, A. Fiore, R. Di Corato, A. Falqui, C. Giannini, E. Micotti, A. Lascialfari, M. Corti, R. Cingolani, T. Pellegrino, P. D. Cozzoli and L. Manna, J. Am. Chem. Soc., 2008, 130, 14771487.

33 S. H. Sun, H. Zeng, D. B. Robinson, S. Raoux, P. M. Rice, S. X. Wang and G. X. Li, J. Am. Chem. Soc., 2004, 126, 273-279. 